\title{
Cytokines produced by susceptible and resistant mice in the course of Paracoccidioides brasiliensis infection
}

V.L.G. Calich and S.S. Kashino
Departamento de Imunologia, Instituto de Ciências Biomédicas, Universidade de São Paulo, São Paulo, SP, Brasil
Correspondence

V.L.G. Calich

Departamento de Imunologia

ICB, USP

Av. Prof. Lineu Prestes, 2415

05508-009 São Paulo, SP

Brasil

Fax: 55 (011) 818-7224

E-mail: vlcalich@biomed.icb2.usp.br

Research supported by FAPESP and CNPq. S.S. Kashino is the recipient of a Doctoral fellowship from FAPESP.

Received October 27, 1997 Accepted January 5, 1998

\section{Abstract}

Paracoccidioidomycosis (PCM) is the most prevalent deep mycosis in Latin America and presents a wide spectrum of clinical manifestations. We established a genetically controlled murine model of PCM, where $\mathrm{A} / \mathrm{Sn}$ mice develop an infection which mimics the benign disease (immune responses which favor cellular immunity) and B10.A animals present the progressive disseminated form of PCM (preferential activation of $\mathrm{B}$ cells and impairment of cellular immune responses). To understand the immunoregulatory phenomena associated with resistance and susceptibility in experimental PCM, A/Sn and B10.A mice were studied regarding antigen-elicited secretion of monokines (TNF- $\alpha$ and TGF- $\beta$ ) and type-1 (IL-2 and IFN- $\gamma$ ) and type2 (IL-4,5,10) cytokines. Total lymph node cells from resistant mice infected ip with P. brasiliensis produced early and sustained levels of IFN- $\gamma$ and IL-2; type- 2 cytokines (IL-4 and IL-5) started to appear 8 weeks after infection. In contrast, susceptible mice produced low levels of IFN- $\gamma$ concomitant with significant levels of IL-5 and IL-10 early in the infection. In the chronic phase of the disease, susceptible animals presented a transitory secretion of IL-2, and IL-4. In the pulmonary infection IL-4, IL-5 and IL-10 were preferentially detected in the lung cells washings of susceptible animals. After in vitro challenge with fungal antigens, normal peritoneal macrophages from B10.A mice secreted high levels of TGF- $\beta$ and low levels of TNF- $\alpha$. In contrast, macrophages from $\mathrm{A} / \mathrm{Sn}$ animals released high levels of TNF- $\alpha$ associated with a small production of TGF- $\beta$. The in vivo depletion of IFN- $\gamma$ not only abrogated the resistance of $\mathrm{A} / \mathrm{Sn}$ mice but also diminished the relative resistance of B10.A animals. The in vivo depletion of IL-4 did not alter the disease outcome, whereas administration of rIL-12 significantly enhanced resistance in susceptible animals. Taken together, these results suggest that an early secretion of high levels of TNF- $\alpha$ and IFN- $\gamma$ followed by a sustained secretion of IL-2 and IFN- $\gamma$ plays a dominant role in the resistance mechanisms to P. brasiliensis infection. In contrast, an early and ephemeral secretion of low levels of TNF- $\alpha$ and IFN- $\gamma$ associated with production of IL-5, IL-10 and TGF- $\beta$ characterizes the progressive disease of susceptible animals.
Key words

- Murine paracoccidioidomycosis

- Genetic resistance

- Cytokines

- Type-1 cytokines

- Type-2 cytokines

- Monokines 


\section{Introduction}

Paracoccidioidomycosis (PCM), caused by the thermally dimorphic fungus Paracoccidioides brasiliensis, is the most prevalent deep mycosis in Latin America. The usual route of infection is the inhalation of fungal particles. Most exposed subjects develop an asymptomatic infection (PCM-infection) although some individuals present clinical manifestations. The disease presents a wide spectrum of clinical and pathological manifestations, ranging from benign and localized to severe and disseminated forms. Patients with benign PCM usually present low levels of specific antibodies and adequate cellular immune responses, while those with the disseminated disease typically show high levels of specific antibodies, polyclonal activation of $B$ cells, antigenemia and impaired cellular immune responses (1).

The experimental murine model of paracoccidioidomycosis

We established a genetically controlled murine model of PCM which allowed us to investigate several parameters of host-parasite interactions.

Eleven different inbred mouse strains infected intraperitoneally (ip) with five million yeast cells from $P$. brasiliensis showed varying patterns of susceptibility as indicated by mortality data. Four basic survival patterns were defined: susceptible (B10.A, B10D2/oSn, B10D2/nSn), intermediate (BALB/c, C57Bl/10, CBA, C3H/FeJ), resistant $(\mathrm{C} 3 \mathrm{H} / \mathrm{HeJ})$ and highly resistant $(\mathrm{A} /$ $\mathrm{Sn}, \mathrm{A} / \mathrm{J}, \mathrm{DBA} / 2$ ). Our results clearly showed that, although mouse strains differ with respect to their susceptibility toP. brasiliensis, those differences are not controlled by the H-2 locus, since susceptible (B10.A) and resistant $(\mathrm{A} / \mathrm{Sn})$ strains share the same $\mathrm{H}-2$ haplotype $\left(\mathrm{H}-2^{\mathrm{a}}\right)$. Since the three most resistant strains (A/J, A/Sn and DBA/2) are C5 deficient, the presence of this complement component does not appear to play a role in the resistance mechanisms to $\mathrm{P}$. brasiliensis infection (2).

As prototypes of the polarized behavior, B10.A and A/Sn mice were studied regarding their innate and acquired immune responses after P. brasiliensis infection. Several isolates (with low and high virulence), different routes of infection as well as several immunological manipulations were used to characterize the immunopathological phenomena associated with resistance and susceptibility to this fungal agent. Most of those results were recently reviewed (3) and clearly show the diverging immune responses mounted by susceptible and resistant animals. Table 1 presents the most important results obtained in our experimental model, and clearly shows that resistance is associated with immune responses which favor cellular immunity and activation of phagocytes, whereas susceptibility is associated with impairment of cellular immune responses and preferential activation of B cells. This pattern of immunological reactivity, also observed in other chronic infectious diseases, led us to postulate that resistance in experimental PCM is associated with a preferential Th1 activation whereas susceptibility is associated with a predominant $\mathrm{Th} 2$ pattern $(3,4)$.

To better understand the immunoregulatory phenomena associated with resistance and susceptibility in experimental PCM, A/ Sn and B10.A mice were studied regarding their secretion of monokines (TNF- $\alpha$ and TGF- $\beta$ ), and type-1 (IL-2 and IFN- $\gamma$ ) and type-2 (IL-4, IL-5, IL-10) cytokines. Since our laboratory has also established experimental protocols which lead to protection or exacerbation of the disease developed by susceptible animals, this model was used to further investigate the association of cytokine production and disease outcome. In addition, the pulmonary model of infection was used to determine the effect of in vivo depletion of IFN- $\gamma$ and IL-4 as well as the effect of 
early rIL-12 administration on susceptibility to $\mathrm{P}$. brasiliensis infection.

Cytokines production in the intraperitoneal model of infection

Cells from both distant and local lymph nodes were obtained at different times (1-16 weeks) after ip infection of resistant and susceptible mice with five million yeast cells of a virulent isolate $(\mathrm{Pb} 18)$. Cells were pooled and cultured in the presence of a cell-free antigen (5). Supernatants were obtained and cytokines assayed by capture ELISA using monoclonal antibodies against murine cytokines.

Lymphocytes from resistant mice produced IL-2 and IFN- $\gamma$ at almost all time points analyzed. The high production of IFN$\gamma$ at the 2nd week after infection and the increasing levels of IL-2 from the second week onwards were noteworthy. On the other hand, IL-4 and IL-5 were detected only after 8 weeks of infection.

In contrast, total lymph node cells from susceptible animals secreted low levels of
IFN- $\gamma$ (2nd week) and IL-2 (8th and 16th weeks). The cytokine IL-10 was produced at almost all post-infection periods whereas IL-4 was detected only at week 12 after infection.

Resistant animals produced IL-5 late in the disease (from the 8th week on), but susceptible mice showed two peaks of IL-5 production at the 1st and 12th weeks postinfection. Since eosinophils are positively regulated by IL-5 (6), we examined the presence of these cells in the bone marrow of resistant and susceptible mice after P. brasiliensis infection. Interestingly, two eosinophilia peaks were detected in susceptible animals concomitant with IL-5 peaks observed in lymph node cell supernatants. Despite the late IL-5 production by resistant animals, no eosinophilia was detected in their bone marrow smears. This result suggests that in the presence of significant levels of type 1 cytokines (IL-2 and IFN- $\gamma$ ) IL-5 is unable to induce enhanced eosinophil maturation $(7,8)$.

The production of the inflammatory monokine TNF- $\alpha$ was examined after in vi-

\begin{tabular}{lll}
$\begin{array}{l}\text { Table } 1 \text { - Immunopathological characteristics of susceptible (B10.A) and resistant (A/Sn) mice infected with } \\
\text { the virulent Pb18 P. brasiliensis isolate. }\end{array}$ & \\
$\begin{array}{l}\text { Mice were infected ip with } 5 \times 10^{6} \text { yeast cells and the observations made in the course of infection (15 days } \\
\text { to } 6 \text { months). }\end{array}$ & Susceptible mice & \\
\hline Immunopathological & (B10.A) & Resistant mice \\
characteristics & Progression & (A/Sn) \\
\hline Infection outcome & Numerous, non-organized & Cure \\
Granulomatous lesions & & Few, organized \\
Viable yeasts (chronic phase) & Numerous & \\
Lungs & Numerous & Absent \\
Epiplon/pancreas & Numerous & Absent \\
Liver & Numerous & Absent \\
Spleen & Low, transient & Scarce \\
PMN activation & Present, late & High, sustained \\
Macrophage activation & High, not sustained & High, early \\
la expression & High & High, sustained \\
Specific antibody levels & IgG2b and lgA & Low \\
Predominant isotypes & Present & IgG2a \\
Polyclonal B cell activation & Anergy & Absent \\
Specific DTH reactions & Present & Present \\
Bone marrow eosinophilia & Absent
\end{tabular}


tro infection of normal B10/A and $\mathrm{A} / \mathrm{Sn}$ peritoneal macrophages with yeast cells. Supernatants obtained after several co-cultivation periods and from various yeast/macrophage ratios were assayed for TNF- $\alpha$ activity using a cytotoxicity assay and rTNF- $\alpha$ as standard. Macrophages from resistant animals released higher levels of TNF- $\alpha$ than macrophages from susceptible mice (Sarti MSMV and Calich VLG, unpublished results).

Since the regulatory cytokine TGF- $\beta$ functions as a switch factor for IgG2b and IgA isotypes (9), and susceptible mice presented an enhanced ability to secrete these isotypes $(3,10)$, secretion of TGF- $\beta$ was studied in the ip model of $\mathrm{P}$. brasiliensis infection. The production of this cytokine was measured using a biological assay and $\mathrm{rTGF}-\beta$ as standard. Peritoneal macrophages from infected B10.A and $\mathrm{A} / \mathrm{Sn}$ mice were cultured in vitro in the presence and in the absence of $P$. brasiliensis antigens. In both experimental situations, and early in the infection, B10.A macrophages produced significantly higher titers of active TGF- $\beta$ than those recovered from the peritoneal cavity of resistant animals. Antigen addition to the cell cultures enhanced the observed differences (11).

The ability of resistant animals to produce TNF- $\alpha$, IFN- $\gamma$ and IL-2 during early phases of infection appears to meet the required conditions to induce a preferential Th1-type $T$ cell response. In addition, early in the disease, type-2 cytokines are not released (IL-4 and IL-5) and an inhibitory cytokine is produced in low amounts (TGFB). This preferential type 1 response agrees with the main immunological phenotypes expressed by resistant animals, i.e., self-healing disease characterized by few and wellorganized granulomata, decreasing fungal loads in several organs/tissues, positive delayed type hypersensitivity (DTH) responses, activation of macrophage and polymorphonuclear (PMN) cells, IgG2a as the main immunoglobulin isotype, absence of circulat- ing fungal antigens, absent polyclonal B cell activation and absent bone marrow eosinophilia $(3,7,8)$.

Eight weeks after ip infection resistant animals do produce type 2 cytokines: IL-5, IL-4 and IL-10. Secretion of IL-5 becomes sustained through the chronic phase, while IL-4 is transiently produced. The presence of type 2 cytokines appears to be non-deleterious to A/Sn mice since they are produced concomitantly with type 1 cytokines. IL-4 secretion appears to be ineffective in driving the bulk of $\mathrm{T}$ cell responses to the Th2 polarized phenotype. By that time (8th week), the $T$ cells that have acquired the Th1 phenotype are probably resistant to the effects of IL-4. One possible role of IL-10 in the present scenario might be to dampen the production of type 1 cytokines thus restraining their inflammatory effects on host tissues. Consistent with these concepts, knocking out the IL-10 gene induces high susceptibility to Toxoplasma gondii due to uncontrolled Th1 responses (12).

The immunoregulatory mechanisms associated with genetic susceptibility to $P$. brasiliensis are less clear. However, early in the infection, secretion of low levels of IFN- $\gamma$ is concomitant with production of regulatory (TGF-B, IL-10) and type 2 (IL-5) cytokines. These cytokines could account for the major immunopathological characteristics of susceptible hosts. The early TGF- $\beta$, IL-10 and IL-5 secretion is phenotypically translated into impaired macrophage and PMN activation, DTH anergy, enhanced IgG2b and IgA specific antibody production and bone marrow eosinophilia. This type of activation leads to a progressive disease with increasing fungal loads in many non-organized granulomatous lesions $(3,7,8,10)$.

The absence of IL- 4 secretion early in the infection makes it difficult to ascribe susceptibility to a typical activation of $\mathrm{CD} 4{ }^{+} \mathrm{Th} 2$ cells $(13,14)$. Since IL-10 is produced by several cell types, the early secretion of this cytokine cannot be used as a marker of Th2 
cell activation. However, the early bone marrow eosinophilia associated with IL-5 secretion suggests a Th2-mediated activity.

An overall analysis of cytokine production profiles and immunopathological features displayed by resistant and susceptible mice indicates that resistance to $P$. brasiliensis infection is associated with early activation of immune mechanisms which drive the immune response to a preferential type 1 phenotype, whereas susceptibility is linked to early production of inhibitory mediators which downregulate IFN- $\gamma$ production and suppress the development of protective type 1 immunity.

Cytokines in the protection and exacerbation models of PCM

Experimental studies using other pathogenic fungi have revealed that the route of infection influences the immune response profiles of infected animals (15).

When the subcutaneous (sc) route of infection was used, strain differences in resistance to $\mathrm{Pb} 18$ infection could not be observed. Regardless of the mouse strain, the disease was not lethal and anatomopathological studies revealed absence of lesions in all organs/tissues examined characterizing a self-healing and benign infection. Despite the equivalent disease outcome of sc infected B10.A and A/Sn mice, susceptible animals showed significantly higher DTH responses than their resistant counterparts $(3,16)$. Furthermore, after sc infection, susceptible animals presented DTH reactions with fungal infecting doses 100-fold lower than those required to prime resistant animals $\left(5 \times 10^{4}\right.$ yeast cells for B10.A and $5 \times$ $10^{6}$ yeasts for $\mathrm{A} / \mathrm{Sn}$ mice). In addition, the higher DTH reactivity of B10.A mice was associated with a higher production of IgA, IgG1, IgG3 and IgG2b specific antibodies indicating a concomitant activation of Th1 and Th2 cells. In summary, after sc infection, both resistant and susceptible mice pre- sented evident humoral and cellular immune responses, but B10.A animals were much more reactive than $\mathrm{A} / \mathrm{Sn}$ mice. These results clearly show that potent immunoregulatory mechanisms account for the lack of stable cell-mediated immunity in susceptible animals after intraperitoneal, intravenous and intratracheal (ip, iv, and it) routes of infection. These mechanisms, however, are absent in infection induced by the sc route.

Since susceptible animals do not have an intrinsic deficiency in the ability to mount an effective cellular immune response, they can be manipulated in various ways, in order to induce protective immunity. Therefore, a protective immunization protocol was developed employing B10.A mice which were inoculated by the sc route with five million $\mathrm{Pb} 18$ yeast cells. At the optimal time for development of a DTH response (2 weeks after infection), animals were challenged ip or iv with a lethal dose of the same $\mathrm{Pb}$ isolate. The ip-challenged animals survived significantly longer than non-vaccinated controls. Surprisingly, the animals challenged iv showed increased mortality compared to the iv-infected controls. Thus, the same immune response induced by sc infection led to opposite disease outcomes depending on the route of challenge (16).

The protection/exacerbation models of PCM were further explored. The lower mortality observed after sc priming and ip challenge was associated with lower fungal loads in several organs, sustained DTH responses (reversal of the anergy induced by the ip route), higher lymphoproliferative responses, increased production of IgM, IgG1 and IgG3 specific antibodies and enhanced production of IL-2 and IL-10 by antigen-stimulated lymph node cells. In conclusion, the protection model of PCM showed that susceptible animals can develop a protective immunity which is associated with secretion of higher levels of IL-2 and IL-10 and the reversal of DTH anergy. This model of PCM indicates that a balanced $\mathrm{Th} 1 / \mathrm{Th} 2 \mathrm{immune}$ response is 
sufficient to confer protection to susceptible hosts $(16,17)$.

The exacerbated disease induced by iv challenge in susceptible animals was further studied. Despite the higher mortality, the sc + iv treated mice did not show an increased fungal load in the examined organs. However, those animals were persistently anergic in terms of DTH reactions (like their iv infected counterparts), showed suppressed IL-2 production, presented higher levels of $\operatorname{IgM}$ and $\operatorname{IgA}$ specific antibodies and decreased levels of IgG2a antibodies, and secreted enhanced levels of IL-4, IL-5 and IL10. In this model of exacerbated disease, the association of DTH anergy with enhanced secretion of IL-4, IL-5 and IL-10 points out the deleterious effects of type 2 cytokines $(16,17)$.

Cytokines in the pulmonary
model of infection

After it infection with one million yeast cells of P. brasiliensis, A/Sn and B10.A mice maintained the same polarized patterns of resistance as those observed with the ip route of infection. A/Sn mice developed a chronic benign infection limited to the lungs, whereas B10.A mice presented a chronic progressive disseminated disease. Results obtained in this model suggested that resistance to pulmonary PCM is associated with $\mathrm{T}$ cell, macrophage and $\mathrm{B}$ cell activities that are mediated by IFN- $\gamma(10)$.

To test this hypothesis we determined the effect of the in vivo IFN- $\gamma$ depletion by a neutralizing monoclonal antibody (XMG1.2). We observed an exacerbation of the pulmonary infection and an earlier fungal dissemination to the liver and spleen in both resistant and susceptible mice infected by the pulmonary route. Neutralization of IFN- $\gamma$ was accompanied by impairment of antigenspecific cellular immune responses resulting in reduced DTH reactions. The depletion of IFN- $\gamma$ increased the production of IgG1 and
IgG2b antibodies in susceptible mice while the isotypic pattern of resistant animals ( $\mathrm{IgG} 2 \mathrm{a}$ and $\mathrm{IgG} 3$ ) reverted to a predominant IgG1 and IgG2b production. Therefore, depletion of endogenous IFN- $\gamma$ abrogated the resistance of $\mathrm{A} / \mathrm{Sn}$ mice but also diminished the relative resistance of B10.A animals (18).

Lung cell washings of susceptible animals were analyzed 4 and 8 weeks after it infection. Low levels of type 1 cytokines (IL-2 and IFN- $\gamma$ ) were detected, accompanied by a consistent presence of high levels of IL-4, IL-5 and IL-10. In addition, when spleen and lymph node cells were cultured in the presence of $\mathrm{P}$. brasiliensis antigen, only IL-10 was significantly released.

The development of $\mathrm{Th} 2$ cells requires IL-4 during priming of naive Th cells $(13,14)$ and the in vivo depletion of this cytokine induces a healing phenotype in hosts naturally susceptible to experimental candidiasis or leishmaniasis $(19,20)$. To better understand the effect of type 2 cytokines on the pulmonary PCM of susceptible animals, in vivo depletion of IL-4 with a specific neutralizing monoclonal antibody (11B11) was performed. This treatment did not alter the disease outcome as revealed by the equivalent number of viable yeast cells in the lungs, spleen and liver of anti-IL-4-treated and untreated B10.A mice. In addition, IL-4 neutralization did not change the predominant secretion of type 2 cytokines in the lungs, spleen and lymph nodes. Also, no significant differences were noted in the pulmonary histopathological features (21). These findings suggest that IL-4 does not play a prominent role in host susceptibility to P. brasiliensis infection. This conclusion is different from those obtained in polarized Th1/Th2 models of infection employing several microorganisms, where abrogation of endogenous IL-4 leads susceptible hosts to a healing phenotype $(13,19,20)$. In another experimental model of pulmonary PCM using BALB/c mice, Hostetler et al. (22) demon- 
strated that early in vivo treatment with $8 \mathrm{mg}$ of anti-IL-4/mouse had a beneficial effect on the disease. Since we used $1 \mathrm{mg} /$ mouse per week for 8 weeks, other protocols using higher amounts of anti-IL-4 should be tested in our experimental model.

Interleukin-12 is a cytokine produced by macrophages in response to infection with various organisms which acts in synergy with TNF- $\alpha$ and IL-2 to induce the generation of IFN- $\gamma$ by NK cells and acts on both $\mathrm{CD}^{+} \mathrm{T}$ and NK cells to enhance their cytotoxic activity. Importantly, IL-12 also conditions naive helper cells to differentiate to the Th1 pathway and stimulates $\mathrm{Th} 2$ cells to transiently produce IFN- $\gamma$ (reviewed in Ref. 23 ). If type 1 responses are protective in $P$. brasiliensis infection, it would be expected that manipulations which enhance type 1 cytokine production would confer some resistance to P. brasiliensis susceptible hosts. To examine this hypothesis, rIL-12 (a generous gift of S. Wolf, Genetics Institute, Boston) was administered ip ( $1 \mu \mathrm{g} /$ mouse per day for 5 days starting at day 0 after infection) to susceptible B10.A mice. Animals were tested at weeks 4 and 8 after infection. Indeed, early treatment with IL-12 had profound effects on the disease development of B10.A mice. Recombinant IL-12-treated mice had impaired fungal dissemination to liver and spleen, concomitant with a significant reduction in pulmonary secretion of type 2 cytokines. Interestingly, rIL-12 also diminished the low levels of type 1 cytokines (IL-2 and IFN- $\gamma$ ) present in the lung cell washings. Noteworthy was the decrease of IL-10 in the lungs and in the supernatants of antigen-stimulated lymph node cells. The protective activity of rIL-12 was accompanied by an increased mononuclear cell infiltration in the lungs detected by histopathological studies (21).

The ability of rIL-12 to improve PCM in normally susceptible B10.A mice strongly supports a role of this cytokine in the induction of protective immunity toP. brasiliensis infection. Furthermore, this study suggests

\begin{tabular}{|c|c|c|}
\hline \multicolumn{3}{|c|}{$\begin{array}{l}\text { Mice were infected ip or it with } 5 \times 10^{6} \text { or } 1 \times 10^{6} \text { yeast cells, respectively. For protocols of in vivo } \\
\text { manipulations see text. ND, Not done. }\end{array}$} \\
\hline Characteristics & $\begin{array}{l}\text { Susceptible mice } \\
\text { (B10.A) }\end{array}$ & $\begin{array}{l}\text { Resistant mice } \\
\text { (A/Sn) }\end{array}$ \\
\hline IL-2 and IFN- $\gamma$ secretion & $\begin{array}{l}\text { Low, transitory (ip) } \\
\text { Persistent (it) }\end{array}$ & $\begin{array}{l}\text { High, persistent (ip) } \\
\text { Persistent (it) }\end{array}$ \\
\hline \multirow[t]{2}{*}{ IL-4 secretion } & Late, transitory (ip) & Late, transitory (ip) \\
\hline & High, persistent (it) & Low, persistent (it) \\
\hline \multirow[t]{2}{*}{ IL-5 secretion } & Early + late (ip) & Late (ip) \\
\hline & High, persistent (it) & Low, persistent (it) \\
\hline \multirow[t]{2}{*}{ IL-10 secretion } & Early peak (ip) & Late peak (ip) \\
\hline & High, persistent (it) & Low, persistent (it) \\
\hline TNF- $\alpha$ production & Low & High \\
\hline TGF- $ß$ secretion & High & Low \\
\hline Protection $(s c+i p)$ & Increased IL-2 and IL-10 & ND \\
\hline Exacerbation $(s c+i v)$ & Increased IL-4, IL-5 and IL-10 & ND \\
\hline IL-4 depletion & No effect & ND \\
\hline IFN- $\gamma$ depletion & Increased susceptibility & Reversal of resistance \\
\hline rlL-12 administration & Protective & ND \\
\hline
\end{tabular}


that the quantity of IL-12 induced by P. brasiliensis following pulmonary infection of susceptible animals is low and insufficient to induce a preferential Th1-type response. This amount is presumably well below that administered in the experimental protocol using exogenous IL-12. Since we have also observed a critical role of IFN- $\gamma$ in resistance to pulmonary PCM, it is tempting to speculate that IL-12 functions through its ability to induce IFN- $\gamma$ production by both $\mathrm{T}$ cells and NK cells. However, increased production of IFN- $\gamma$ was not observed after 4 and 8 weeks of infection. Measurements of cytokines such as IFN- $\gamma$ at earlier periods of infection will help to elucidate the protective effects of IL-12 in experimental PCM.

\section{Concluding remarks}

The results of our cytokine studies in the isogenic murine model of PCM are summarized in Table 2. The findings are consistent with a protective role of IL-12, IFN- $\gamma$ and IL2 production, and strongly support the hypothesis of preferential type 1 responses associated with the resistant phenotype. On the contrary, susceptibility is linked to IL-4, IL-
5 , IL-10 and TGF- $\beta$ production, leading us to propose that type 2 immune responses or production of regulatory cytokines are responsible for progressive PCM. Further experiments aimed at determining the function and cytokine patterns of T, B and NK cells will help us to better understand the immunoregulatory mechanisms associated with resistance and susceptibility to $P$. brasiliensis infection.

Our knowledge about the immune mechanisms underlying the pathogenesis of PCM and protection against $P$. brasiliensis infection is still fragmentary. However, cytokine studies have provided new insights into the host-parasite interactions and opened perspectives for the design of new prophylactic and therapeutic strategies.

\section{Acknowledgments}

The authors acknowledge the combined efforts from members of the laboratory (E. Burger, L.M. Singer-Vermes and C.A.C. Vaz) and postgraduate students (R.A. Fazioli, C. Arruda, L.E. Cano, S.M.D. Moraes, F.R.P. Nascimento and K.C. Rocha) to study the resistance mechanisms in experimental PCM.

\section{References}

1. Restrepo A (1988). Immune responses to Paracoccidioides brasiliensis in human and animal hosts. In: McGinnis MR (Editor), Current Topics in Medical Mycology. Vol. 2. Springer Verlag, New York, 239275.

2. Calich VLG, Singer-Vermes LM, Siqueira AM \& Burger E (1985). Susceptibility and resistance of inbred mice to Paracoccidioides brasiliensis. British Journal of Experimental Pathology, 66: 585-594.

3. Calich VLG, Singer-Vermes LM, Russo M, Vaz CAC \& Burger E (1994). Immunogenetics in paracoccidioidomycosis. In: Franco M, Lacaz CS, Restrepo AM \& Del Negro G (Editors), Paracoccidioidomycosis. CRC Press, Boca Raton, FL, 151-178.

4. Murphy JW, Wu-hsieh A, Singer-Vermes LM, Ferrante A, Moser S, Russo M, Vaz
CAC, Burger E, Calich VLG, Kowanko IC, Rathjen DA, Martin AJ, Buci RC \& Chen O (1994). Cytokines in the host response to mycotic agents. Journal of Medical and Veterinary Mycology, 32: 203-210.

5. Camargo ZP, Taborda CP, Rodrigues EG \& Travassos RL (1991). The use of cellfree antigens of Paracoccidioides brasiliensis in serological tests. Journal of Medical and Veterinary Mycology, 29: 31-38.

6. Yamaguchi $Y$, Hayashi $Y$, Sugama $Y$, Miura Y, Kasahara T, Kitamura S, Toridu M, Mita S, Tominaga A, Takatsu K \& Suda I (1988). Highly purified murine interleukin-5 (IL-5) stimulates eosinophil function and prolongs in vitro survival. Journal of Experimental Medicine, 167: 1737-1742.

7. Meloni-Bruneri LH (1995). Produção e mobilização de células sanguíneas, estado de ativação e capacidade fungicida de neutrófilos em paracoccidioidomicose murina experimental. Doctoral thesis, Instituto de Ciências Biomédicas, USP, São Paulo, SP, Brazil.

8. Kashino SS (1997). Produção de citocinas por camundongos resistentes e susceptíveis à infecção pelo Paracoccidioides brasiliensis. Doctoral thesis, Instituto de Ciências Biomédicas, USP, São Paulo, SP, Brazil.

9. Finkelman FD, Holmes J, Katona IM, Urban Jr JF, Beckman MP, Park IS, Schooley KA, Coffman RL, Mossmann TR \& Paul WE (1990). Lymphokine control of in vivo immunoglobulin isotype selection. Annual Review in Immunology, 8: 303-333.

10. Cano LE, Singer-Vermes LM, Vaz CAC, Russo M \& Calich VLG (1995). Pulmonary 
paracoccidioidomycosis in resistant and susceptible mice: Relationship among progression of infection, bronchoalveolar cell activation, cellular immune responses and specific isotype patterns. Infection and Immunity, 63: 1777-1783.

11. Moraes SMD, Calich VLG \& Burger $E$ (1996). Susceptible mice to Paracoccidioides brasiliensis infection produce higher levels of TGF- $\beta$ than resistant animals. International Meeting on Cytokines, Angra dos Reis, RJ, Brazil, Abstract 01.56.

12. Gazzinelli RT, Wysocka M, ShartonKersten T, Cheever A, Kühn R, Müller W, Trinchieri $G$ \& Sher A (1996). In the absence of endogenous IL-10, mice acutely infected with Toxoplasma gondiisuccumb due to a lethal immune response dependent on CD4 ${ }^{+} \mathrm{T}$ cells and accompanied by overproduction of IL-12, IFN- $\gamma$ and TNF- $\alpha$. Journal of Immunology, 157: 798-805.

13. Reiner SL \& Locksley RM (1995). The regulation of immunity to Leishmania major. Annual Review in Immunology, 13: 151-178.

14. Seder MD \& Paul WE (1994). Acquisition of lymphokine producing phenotype by CD4+ T cells. Annual Review in Immunology, 12: 635-674.

15. Morozumi PA, Brummer E \& Stevens DA
(1981). Strain differences in resistance to infection reversed by the route of challenge. Infection and Immunity, 34: 623630.

16. Arruda C (1993). Caracterização da infecção subcutânea pelo Paracoccidioides brasiliensis em camundongos isogênicos: uma via que pode induzir proteção ou exacerbação da doença. Master's thesis, Instituto de Ciências Biomédicas, USP, São Paulo, SP, Brasil.

17. Kashino SS, Fazioli RA \& Calich VLG (1996). Cytokine production (IL-2, IFN- $\gamma$, IL-4 and IL-10) in the protection and exacerbation models of murine experimental paracoccidioidomycosis. International Meeting on Cytokines, Angra dos Reis, RJ, Brazil, Abstract 01.55.

18. Cano LE, Kashino SS, Arruda C, André DC, Xidieh CF, Singer-Vermes LM, Vaz CAC, Burger E \& Calich VLG (1998). Protective role of gamma interferon in experimental pulmonary paracoccidioidomycosis. Infection and Immunity, 66 (in press).

19. Romani I, Mencacci A, Grohmann V, Mocci S, Mosci P, Puccetti P \& Bistoni F (1992). Neutralizing antibody to interleukin-4 induces systemic protection and $T$ helper 1 associated immunity in murine candidiasis. Journal of Experimental Medi- cine, 176: 19-25.

20. Sadick MD, Heinzel FP, Holaday BJ, Pu RT, Dawkins RS \& Locksley RM (1990). Cure of murine leishmaniasis with antiinterleukin-4 monoclonal antibody. Journal of Experimental Medicine, 171: 115127.

21. Arruda C, Fazioli RA, Kashino SS, Nascimento FRF, Costa AT, Russo M \& Calich VLG (1996). In vivo treatment with rlL-12 protects susceptible mice from Paracoccidioides brasiliensis infection whereas in vivo neutralization of IL-4 does not alter disease outcome. International Meeting on Cytokines, Angra dos Reis, RJ, Brazil, Abstract 09-04.

22. Hostetler JS, Brummer E, Coffman RI \& Stevens DD (1993). Effect of anti-IL-4, interferon-gamma and an antifungal triazole (SCH42427) in paracoccidioidomycosis: correlation of lgE levels with outcome. Clinical and Experimental Immunology, 94: 11-16

23. Trinchieri G (1995). Interleukin 12: a proinflammatory cytokine with immunoregulatory function that bridges innate resistance and antigen-specific adaptative immunity. Annual Review of Immunology, 13: 251-276. 